\title{
A Room Temperature Indirect Formic Acid Fuel Cell
}

Siu Wa Ting, Fujun Li,Huanqiao Li, Jenkin Tsui, and Kwong-Yu Chan

Department of Chemistry, The University of Hong Kong, Pokfulam Road, Hong Kong.

A room temperature indirect formic acid fuel cell is enabled by a platinum-ruthenium-bismuth mixed metal/metal oxide supported catalyst developed recently at University of Hong Kong [1]. Dehydrogenation of formic acid occurs at room temperature and atmospheric pressure with sufficient hydrogen generation to power a fuel cell. The reaction proceeded in aqueous phase is highly selective to hydrogen and carbon dioxide without detection of carbon monoxide. The gas evolution rate is $400 \mathrm{~mL}$ per hour at $80^{\circ} \mathrm{C}$ when $80 \mathrm{~mL}$ solution of $15 \%$ aqueous formic acid was added to $400 \mathrm{mg}$ catalyst containing $\mathrm{PtRuBiO}_{\mathrm{x}}$ supported on carbon as shown in Fig. 1.

An indirect formic acid fuel cell is built with a fixed bed reforming chamber in which the catalyst is placed. Hydrogen is evolved upon contact of catalysts acid with aqueous formic acid at room temperature. Gas evolution can be stopped or varied by controlling the liquid level in the reforming chamber. Carbon dioxide produced can be separated or adsorbed before allowed to exit.

While reforming can proceed at room temperature, hydrogen evolution increases rapidly with temperature as the dehydrogenation reaction of formic acid on the $\mathrm{PtRuBiO}_{\mathrm{x}}$ catalyst proceeds has a low activation energy barrier of $37.3 \mathrm{~kJ} / \mathrm{mol}$.

\section{References}

[1]. S.W. Ting, S. Cheng, K.Y. Tsang, N. van der Laak, and K.Y. Chan Chem. Commun., 2009, 7333-7335

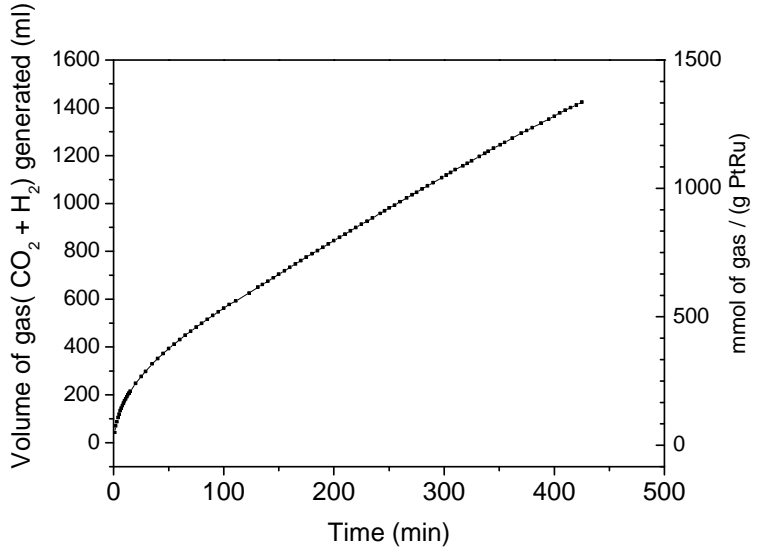

Fig. 1 Decomposition of formic acid on Pt-Ru-BiOx/C $(\mathrm{Pt} / \mathrm{Ru} / \mathrm{Bi} \sim 2: 1: 4)$ at $80^{\circ} \mathrm{C}$ over 7 hours. 